Research Article

\title{
The Ontology-Based Approach Supporting Holistic Energy-Tunnel Design considering Cost, Heat Flux, and System Feasibility
}

\author{
Kun Meng $\mathbb{D}^{1,}, 2$ Chunyi Cui $\mathbb{D}^{2},{ }^{2}$ Cheng Zhang $\mathbb{D}^{3},{ }^{3}$ and Hailong Liu $\mathbb{C}^{2}$ \\ ${ }^{1}$ College of Transportation, Shandong University of Science and Technology, Qingdao 266590, China \\ ${ }^{2}$ Department of Civil Engineering, Dalian Maritime University, Dalian 116026, China \\ ${ }^{3}$ Department of Civil Engineering, Xi'an Jiaotong-Liverpool University, Suzhou 215123, China
}

Correspondence should be addressed to Chunyi Cui; cuichunyi@dlmu.edu.cn

Received 28 October 2021; Accepted 11 November 2021; Published 29 November 2021

Academic Editor: Bingxiang Yuan

Copyright (c) 2021 Kun Meng et al. This is an open access article distributed under the Creative Commons Attribution License, which permits unrestricted use, distribution, and reproduction in any medium, provided the original work is properly cited.

As an emerging geothermal structure, the energy tunnel has been an important part of geothermal engineering. However, the conventional methods for designing energy tunnels mostly rely on complex numerical models. Furthermore, a macrolevel multidomain collaborative design method to consider multiple areas and design indicators is unavailable. This study combined ontology and semantic Web rule language to establish the domain knowledge of energy tunnels which is an enrichment of the conventional ground source heat pump domain knowledge and develop a comprehensive decision-making tool named OntoETS for the design of energy-tunnel systems. The tool can promote the optimal design scheme with an optimal combination of multiple indexes through an analysis of the economy, heat flux, and system feasibility of the energy-tunnel system from a macroperspective by combining multiple domains. Furthermore, a case study was conducted to demonstrate the effectiveness and practicability of the developed holistic decision-making system.

\section{Introduction}

The global demand for clean energy has been increasing in recent years. As a result, an increasing number of countries and regions have begun to develop and use geothermal structures as heat exchangers to extract clean and renewable geothermal energy [1-5], such as deep foundation, shallow foundation, diaphragm wall, tunnel lining, anchor bolt, and pile foundation. Among these, the energy tunnel (see Figure 1) is the most recently developed geothermal structure (developed in the past 20 years). It was first applied to the cooling and heating of buildings by Brandl [6]. Here, the heat exchange pipe of the system is embedded in the tunnel lining to extract the constant geothermal energy. Although its development time is short, the energy tunnel has become an important geothermal energy structure and is being adopted by an increasing number of countries and regions $[7,8]$.
As an important geothermal structure, the energy tunnel has special advantages over other systems. First, it has higher efficiency of heat exchange owing to the large heat exchange volume and additional heat produced by cars. Furthermore, it has longer service life because of being buried in a stable stratum with more stable heat exchange and stress. The most important advantage is that its heat exchanger can be prefabricated and optimized in the factory, wherefore its construction and installation are more convenient and costeffective. The above advantages have made energy tunnel a research hotspot with many scholars conducting substantial research on it. As the most advanced geothermal extraction structure, the energy tunnel has two main design and construction methods. For conventional tunnels such as those constructed by the New Austrian Tunnelling Method, the heat exchange pipe can be installed in the nonwoven geosynthetics and placed between the primary and secondary linings of the tunnel. This is also the first method to 


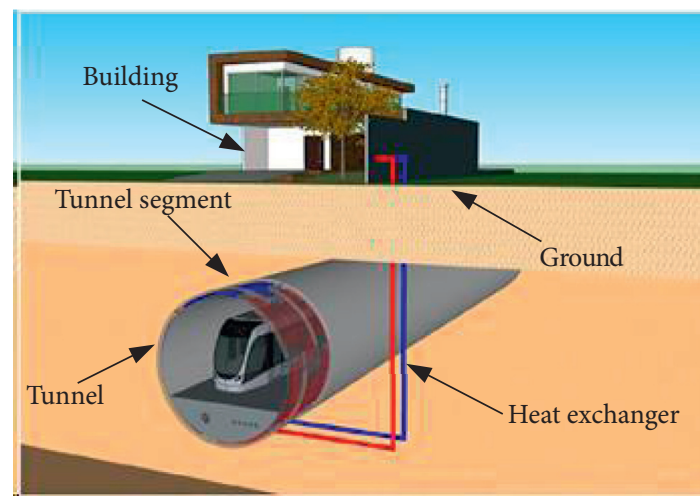

FIGURE 1: Energy-tunnel system.

construct energy tunnels and presents the potential for their construction and promotion. Another method for constructing energy tunnels is becoming feasible with the development of shield tunnels. Herein, the heat exchange pipe of a tunnel can be optimized and placed in prefabricated segments in advance in the factory. Many scholars have conducted substantial research on its feasibility and construction methods $[9,10]$. In general, each segment ring is divided into six-seven segments. Each segment of a heat exchange tube is connected with the adjacent segments, and each group of two or more segment rings form a loop and connect to the main pipeline.

Several scholars have carried out substantial research on the thermal performance of energy tunnels. In terms of analytical models, Islam et al. [11] proposed a simplified heat transfer model for hut systems. Then, Adam and Markiewicz [12] proposed a model for optimizing energy-tunnel designs considering economy. Zhang et al. [13] proposed a new linesource model. It considers both composite media and timedependent boundary conditions and can provide relevant guidelines for the design of energy tunnels.

In terms of numerical simulation and field experiments, Islam et al. [14] conducted a field test in the Nanaori-Toge tunnel. The results verified the feasibility of using energy tunnels for road de-icing. Barla and Perino [15] simulated the thermodynamic performance of an energy tunnel by numerical simulation. The results can provide guidelines for the design of energy tunnels. Furthermore, Yang et al. [16] and Bidarmaghz and Narsilio [17], combined with examples, comprehensively evaluated various factors that affect the heat exchange of an energy tunnel and analyzed its economic feasibility. Because energy tunnels are buried in a shallow stratum with a relatively constant temperature, its mechanical transformation caused by temperature can be omitted for the tunnel design standard. That is, the temperature stress effect of heat exchange need not be considered in the design of energy tunnels.

Although energy tunnels have many advantages, there are certain limitations owing to the short development time. First, it has the disadvantages of conventional ground source heat pump (GSHP) technology. That is, there are few methods and standards with complex steps, which severely limit the design and application of GSHP systems [18].
Second, the current design method cannot actually satisfy the requirements of engineering design [19]. The method mostly relies on complex finite element models owing to its technical complexity. This necessitates substantial labor and calculation capability. Third, the conventional design method of energy tunnels does not have a method to connect and comprehensively consider the multiple domains of energy tunnels from a macroperspective. This prevents the achievement of an optimal match with multiple performance parameters such as cost, heat, and environmental impact. Finally, there is no comprehensive or in-depth unified consensus regarding energy tunnels [20]. The rational design and operation of energy tunnels require a series of subtechnologies and collaboration among different disciplines. Furthermore, information distortion occurs in different stages and the transmission process, which results in unnecessary losses.

As a new semantic web technology, ontology is the fundamental framework of the advanced information society and the research hotspot of artificial intelligence. It provides many concepts and methods to solve problems for the engineering community. It can establish domain knowledge to form a unified consensus to prevent information distortion and can be applied widely in the sharing and exchanging of knowledge across multiple domains [21]. This provides substantial advantages in solving multifield and multiobjective problems [22]. Ugwu et al. [23] developed cross-department architecture collaborative design ontology. It effectively promoted the information interaction between different departments and improved the design efficiency. Hou et al. [24] developed a tool for holistic building design considering building safety and carbon emission based on ontology. Zhang and Issa [25] used IFC standard-based ontology to solve the problem of multiteam collaboration in the AEC field. Anumba [26] studied the integration technology method with ontology as the core to prevent information loss and divergence during project delivery. It substantially promotes project interoperability. In addition, an ontology engineering method is used to facilitate information integration between computer-aided design (CAD) documents and geographic information system (GIS) documents. An ontology-based method is also used to extract information from BIM [27, 28].

According to the abovementioned cases, it is necessary to use ontology to establish the domain knowledge on energy tunnels (which is an enrichment of the conventional ground source heat pump) to ensure the accurate transmission of relevant information between different disciplines and units. To provide accurate domain knowledge and data association, it is also necessary to develop a decision-making tool to holistically design energy tunnels considering multiple indicators from a macroperspective. This study proposed an ontology framework for energy-tunnel design and developed a comprehensive decision-making tool OntoETS (ontology of energy-tunnel systems) to consider multiple indicators such as cost, heat, and system feasibility to promote the optimal design scheme. A case study was conducted to illustrate how the design should use this developed tool and to verify the effectiveness and feasibility of OntoETS. 


\section{Design and Development of OntoETS for Energy-Tunnel Systems}

2.1. Determination of Primary Indictors for Holistic Design of Energy-Tunnel Systems. This section involves the economic performance, heat exchange performance, and feasibility evaluation of an energy-tunnel system. Its safety performance is not considered. Because it is buried in the stratum with stable geothermal condition, its mechanical performance is relatively stable and its temperature stress is smaller than the design stress requirements of the tunnel and can be omitted.

2.1.1. Cost Calculation. The cost calculation includes the heat exchange pipe cost, main conduit cost, cost of the connection pipe between the indoor system and ground source system, heat pump cost, and total cost.

The cost of the heat exchange pipe in the energy tunnel can be calculated by

$$
C^{\mathrm{TP}}=\sum_{i=1}^{n} C_{i}^{\mathrm{TP}} \times L_{i}^{\mathrm{TP}} \times N_{i},
$$

where $i$ represents the $i^{\text {th }}$ prefabricated segment of the tunnel, $C_{i}^{\mathrm{TP}}$ is the price of the heat exchange pipe buried in the $i^{\text {th }}$ prefabricated segment ring of the tunnel, and $L_{i}^{\mathrm{TP}}$ is the length of the heat exchange pipe buried in the $i^{\text {th }}$ prefabricated segment ring of the tunnel. $N_{i}$ represents the number of the $i^{\text {th }}$ prefabricated segment rings, and $C^{\mathrm{TP}}$ is the heat exchange pipe cost of the energy tunnel. The superscript "TP" is the abbreviation of tunnel price.

Then, the main conduit cost can be calculated by

$$
C^{\mathrm{MP}}=\sum_{j=1}^{n} C_{j}^{\mathrm{MP}} \times L_{j}^{\mathrm{MP}} \times N_{j}^{\mathrm{MP}},
$$

where $j$ represents the $j^{\text {th }}$ type of main conduit. $C_{j}^{\mathrm{MP}}$ and $L_{j}^{\mathrm{MP}}$ are the price and length, respectively, of the $j^{\text {th }}$ type of the main conduit. $C^{\mathrm{MP}}$ is the cost of the main conduit of the energy-tunnel system. The superscript "MP" is the abbreviation of main conduit price.

The cost of the connection pipe of the system can be calculated by

$$
C^{\mathrm{CP}}=\sum_{k=1}^{n} C_{k}^{\mathrm{CP}} \times L_{k}^{\mathrm{CP}} \times N_{k}^{\mathrm{CP}},
$$

where ${ }_{\mathrm{k}}$ represents the $k$ th type of connection pipe. $C_{k}^{\mathrm{CP}}$ and $L_{k}^{C P}$ are the price and length, respectively, of the $k$ th type of connection pipe. $C^{\mathrm{CP}}$ is the cost of the connection pipe of the energy-tunnel system. The superscript "CP" is the abbreviation of connection pipe price.

The cost of the heat pump can be calculated by

$$
C^{\mathrm{HP}}=\sum_{l=1}^{n} C_{l}^{\mathrm{HP}} \times N_{l}^{\mathrm{HP}},
$$

where $l$ represents the $l^{\text {th }}$ type of heat pump. $C_{l}^{\mathrm{HP}}$ and $N_{l}^{\mathrm{HP}}$ are the price and number, respectively, of the $l^{\text {th }}$ type of heat pump. Then, $C^{\mathrm{HP}}$ is the cost of the heat pump of the energy- tunnel system. The superscript "HP" is the abbreviation of heat pump price.

Thus, the total cost of the system can be obtained by

$$
C^{\mathrm{E}}=C^{\mathrm{TP}}+C^{\mathrm{MP}}+C^{\mathrm{CP}}+C^{\mathrm{HP}} \text {, }
$$

where $C^{\mathrm{E}}$ is the total cost of the system and $C^{\mathrm{TP}}$ represents the heat exchange pipe cost. $C^{\mathrm{MP}}$ and $C^{\mathrm{CP}}$ are the main conduit cost and connection pipe cost, respectively. $C^{\mathrm{HP}}$ is the heat pump cost.

2.1.2. Calculation of Heat. The heat calculation mainly involves the heat transferred by the tunnel, heat produced by the heat pump, and heat flux of the building. The heat transferred by the tunnel can be calculated by two methods. The first method calculates it using the heat exchange capacity per square meter of the prefabricated segment ring $\left(\mathrm{W} / \mathrm{m}^{2}\right)$, which is determined by a thermal response test (TRT). If the condition for performing thermal response tests is unavailable, it can be calculated by the inflow and outflow temperatures of the system.

Without a TRT, the heat transferred by the tunnel can be calculated by the inflow and outflow temperatures of the system:

$$
Q_{\text {source }}=m c\left|T_{\text {out }}-T_{\text {in }}\right| \text {, }
$$

where $Q_{\text {source }}$ represents the heat transferred by the system from the soil (W), $m$ represents the flow rate of the heat exchange liquid $(\mathrm{kg} / \mathrm{s})$, and $c$ represents the specific heat capacity of the system heat exchange liquid $\left(\mathrm{J} /\left(\mathrm{kg} \cdot{ }^{\circ} \mathrm{C}\right)\right) . T_{\text {out }}$ and $T_{\text {in }}$ represent the inflow and outflow temperatures $\left({ }^{\circ} \mathrm{C}\right)$ of the heat exchange liquid of the system.

The heat transferred by the tunnel can be calculated by the heat exchange per unit area of the tunnel, which is determined by a thermal response test. Then, the total area from which the system can extract heat can be obtained:

$$
A_{i}^{\text {exchange }}=2 \times \pi \times R_{i} \times L_{i} \times N_{i},
$$

where $i$ represents the $i^{\text {th }}$ prefabricated segment ring of the tunnel and $R_{i}$ is the radius (m) of the $i^{\text {th }}$ type of precast segment ring. $L_{i}$ and $N_{i}$ are the length (m) and number, respectively, of the $i^{\text {th }}$ type of precast segment ring. Then, $A_{\text {exchange }}$ represents the area $\left(\mathrm{m}^{2}\right)$ of the $i^{\text {th }}$ type of segment ring for heat exchange.

Thus, the heat exchanged by the tunnel can be obtained:

$$
Q_{\text {source }}=\sum_{i=1}^{n} A_{i}^{\text {exchange }} \times q_{i},
$$

where $i$ represents the $i^{\text {th }}$ prefabricated segment ring of the tunnel and $A_{\text {exchange }}$ represents the area $\left(\mathrm{m}^{2}\right)$ of the $i^{\text {th }}$ type of segment ring for heat exchange. $q_{i}$ is the heat exchange per unit area $\left(\mathrm{W} / \mathrm{m}^{2}\right)$ of the $i^{\text {th }}$ type segment ring installed with a heat exchange tube, which is of the air type, ground source type, or dual-purpose type. Then, $Q_{\text {source }}$ is the heat transferred by the tunnel (W).

Then, the heat produced by the heat pump can be calculated by [29] 
TABLE 1: Details of system evaluation.

\begin{tabular}{lll}
\hline Evaluation & Formula & Illustration \\
\hline Feasible & $q_{\text {heat }}>q_{0}$ & The heat flux provided by the system is higher than the required heat flux of the building \\
Not feasible & $q_{\text {heat }}<q_{0}$ & The heat flux provided by the system is lower than the required heat flux of the building \\
\hline
\end{tabular}

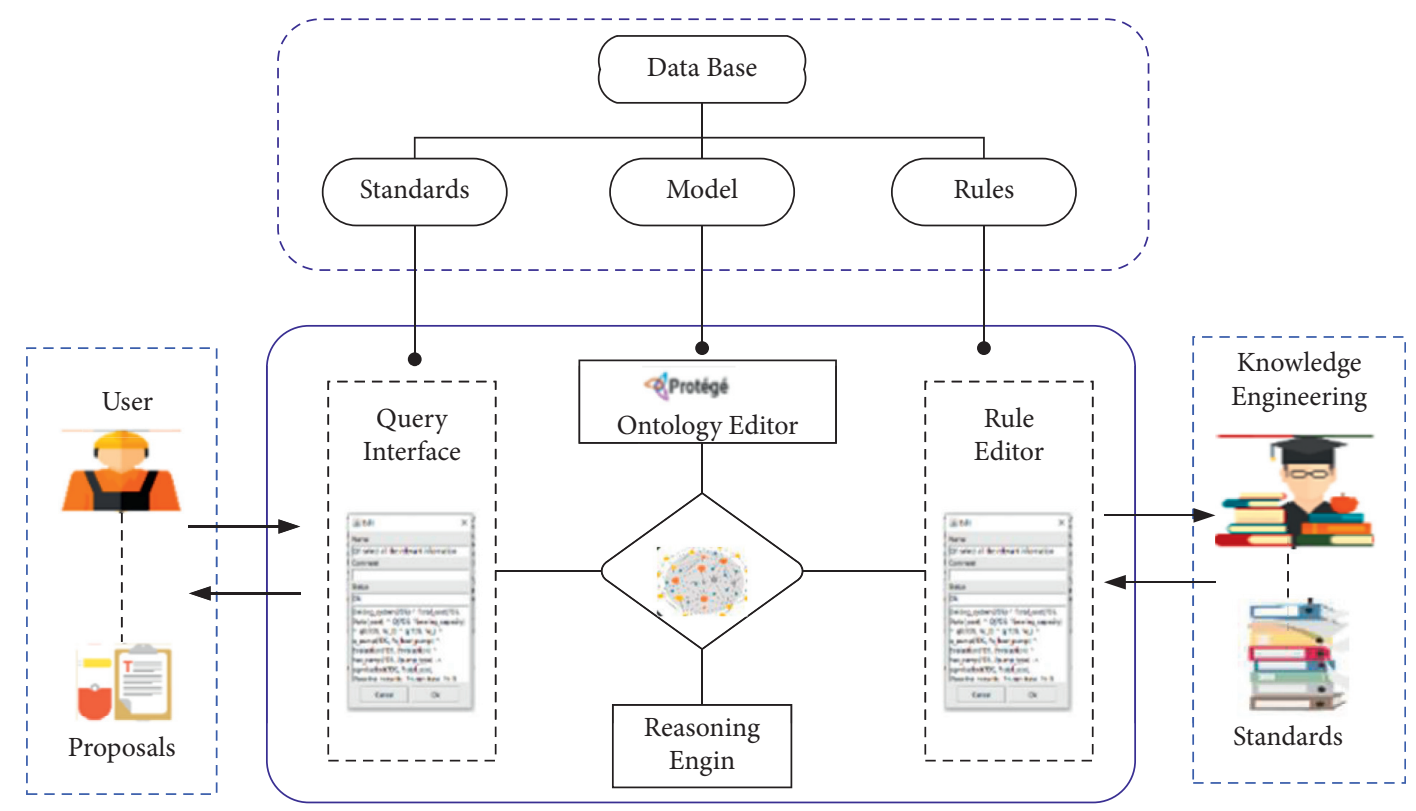

FIGURE 2: Framework of the OntoETS comprehensive decision-making system.

$$
Q_{\text {heat }}=\frac{\mathrm{COP}}{\mathrm{COP}-1} \times Q_{\text {source }} \text {, }
$$

where COP is the performance coefficient of the heat pump [30] and $Q_{\text {source }}$ is the total heat transferred by the energy tunnel (W). Therefore, $Q_{\text {heat }}$ is the heat produced by the heat pump. Then, the heat flux $\left(\mathrm{W} / \mathrm{m}^{2}\right)$ of a building can be obtained as follows:

$$
q_{\text {heat }}=\frac{Q_{\text {heat }}}{\mathrm{A}_{\text {heat }}}
$$

where $Q_{\text {heat }}$ represents the total heat provided by the system and $A_{\text {heat }}$ is the area of the building. Then, $q_{\text {heat }}$ is the heat flux provided to the building by the system.

2.1.3. System Evaluation. To better apply the energy-tunnel system, the developed system considers the heat flux as the standard to evaluate the feasibility of the design scheme, which is mainly divided into feasible and infeasible. The evaluation rules are shown in Table 1.

\subsection{Design and Development of OntoETS}

2.2.1. System Framework and User Guidelines for OntoETS. The developed comprehensive decision-making system OntoETS consists mainly of four parts: database, knowledge management system, rule editor, and query interface (see Figure 2).
The domain knowledge, standards, and ontology models of the energy tunnel are stored in the database in the form of an OWL file to be used at any time. The knowledge management system can edit and manage the ontology model of the energy tunnel. This study used Protégé 5.2 as the development platform for the ontology model. The Protégé platform is an open-source platform created by Stanford University aiming to provide a tool to construct domain models and knowledge-based applications with ontologies [31]. The rule editor can help the developer transfer the specifications and calculation methods of the tunnel and GSHP into logical rules such as SWRL rules according to the characteristics of the energy tunnel. The query part is used by designers, who input the design scheme to be evaluated and optimized through the management platform. Then, users can input the relevant information to query and select the optimal design scheme through the query part. The system components that are necessary to achieve the requirements and preset functions of the development system are shown in Figure 2.

2.2.2. Development of OntoETS. The three necessary steps for ontology development are knowledge identification, knowledge specification, and knowledge refinement. In the knowledge identification step, the scope and domain of the energy tunnel need to be identified. The OntoETS decisionmaking system developed in this study mainly involves the fields of the tunnel (design and construction) and building 


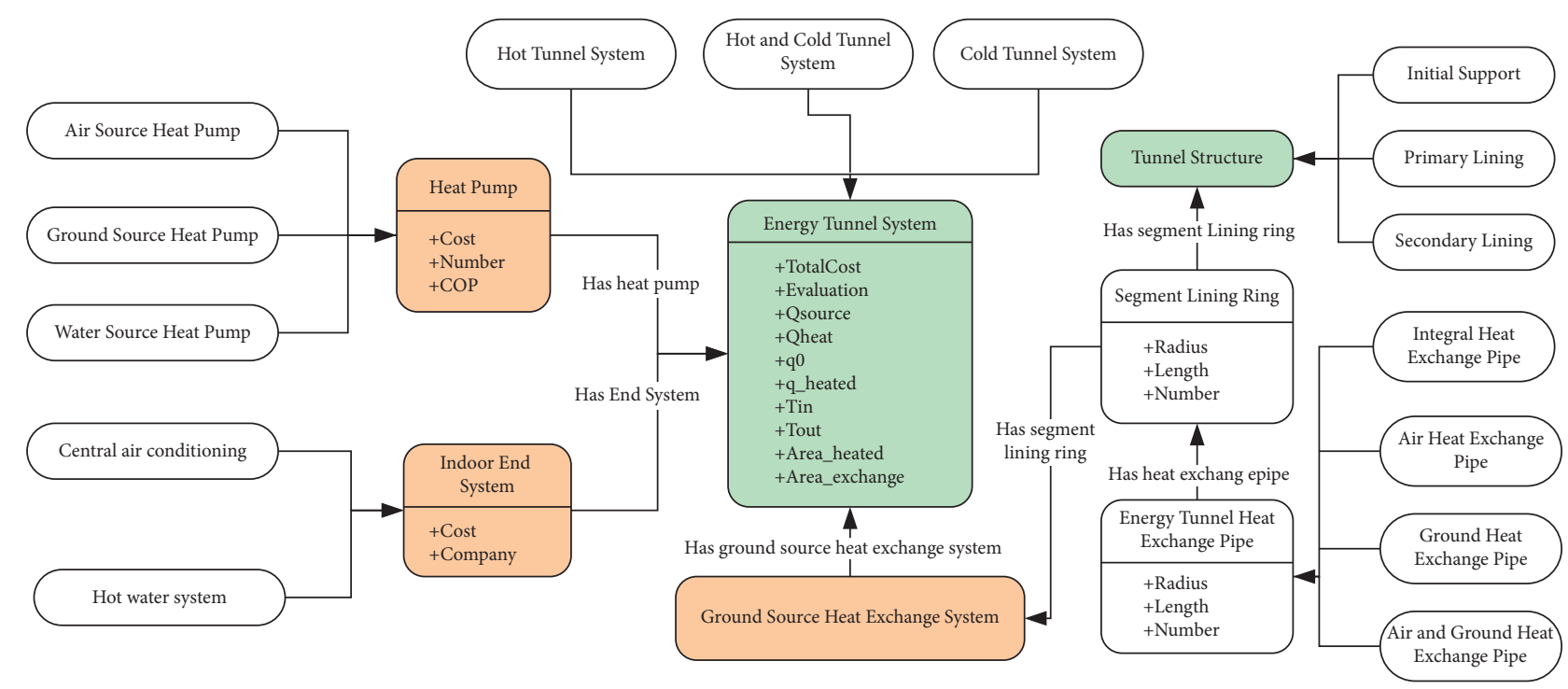

FIGURE 3: UML flowchart of the OntoETS comprehensive decision-making system.

TABLE 2: Question table for knowledge identification of the energy-tunnel system.

Questions

What is the purpose of this ontology?

What are the domain and scope of this ontology?

Main users of this ontology?

What is the function of this ontology?

What elements are involved in this ontology?

What are the design variables of energy tunnel The number of segment rings and type of heat exchange tube in the segment (such as air in this ontology?

What are the macroindicators to evaluate the energy-tunnel system?

Answers

Development of the domain knowledge of energy tunnel to enrich the domain knowledge of conventional GSHP and to evaluate the design scheme of energy-tunnel systems from the macroperspective and, thereby, provide optimization guidelines to promote the optimal design scheme

Tunnel engineering, GSHP system, and building HVAC

Tunnel designers and HVAC designers

It is applicable to the feasibility evaluation and simple optimization carried out in the early stage of energy-tunnel design

Tunnel structure, GSHP system, materials, etc., including heat pump type, pipeline, heat exchanger, lining, segment, and other details

type, ground source type, and dual-purpose type)

The total cost, heat exchanged, and feasibility evaluation based on the heat flux provided by the system for measuring the economy, heat exchange performance, and system feasibility of energy-tunnel systems to provide a macroevaluation and optimization guidelines. In the knowledge specification step, a semiformal specification of the energy tunnel needs to be established to guide the ontology development. That is, a unified modeling language (UML) flowchart of OntoETS is established to guide the establishment of the model as shown in Figure 3. In the final step (knowledge refinement), the developed ontology model needs to be validated and refined (e.g., verification of semantics, syntax, and rules) to prevent errors and redundancy.

The OntoETS decision-making system developed in this study is related mainly to tunnel engineering; building cooling and heating; and the evaluation of the economy, heat exchange performance, and building heat flux of the energytunnel system. The main concepts and terms of the system follow "Industry Foundation Class" (IFC) Standard and are with reference to the existing ontology models of the energy tunnel and GSHP [32]. The hierarchical relationship between the main concepts and terms is shown in Figure 3. Ontology development 101 [33] was considered as the guideline to develop the ontology model of the energy tunnel as follows.

(1) Determination of the Scope and Domain of the Energy Tunnel. The ontology's domain and scope are the most fundamental aspects. These affect the quality of the ontology model. Hence, both the present scenario and likely future scenarios should be considered while determining the domain and scope. In this step, the scope and domain of the energy-tunnel ontology can be determined by asking a few fundamental questions, as shown in Table 2.

The domain and scope of energy tunnels can be obtained by asking the questions given in Table 2. In the ontology development step, such questions can be asked at any time to prevent missing or redundant elements. 


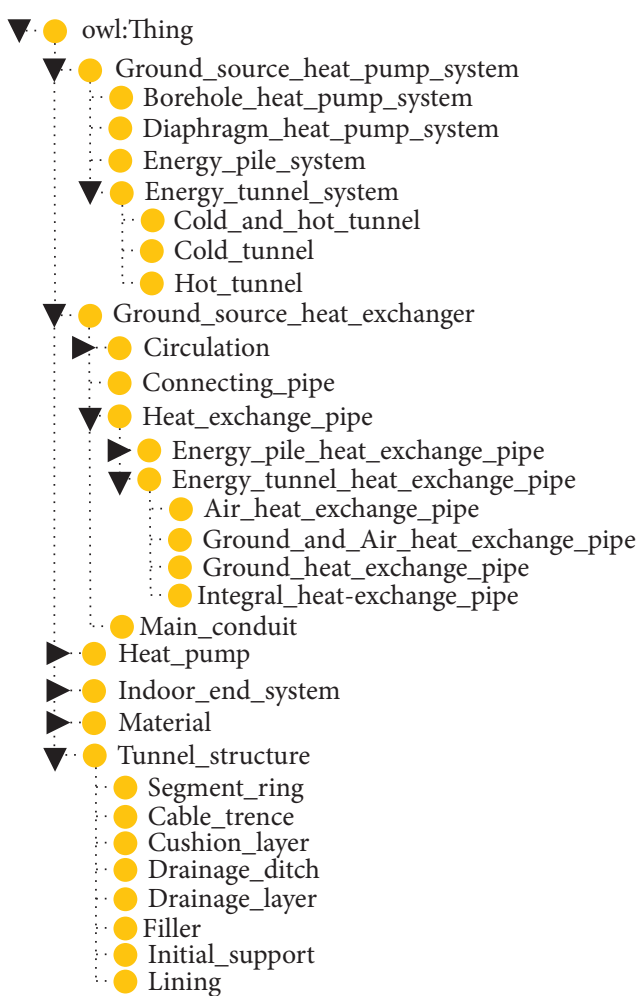

(a)
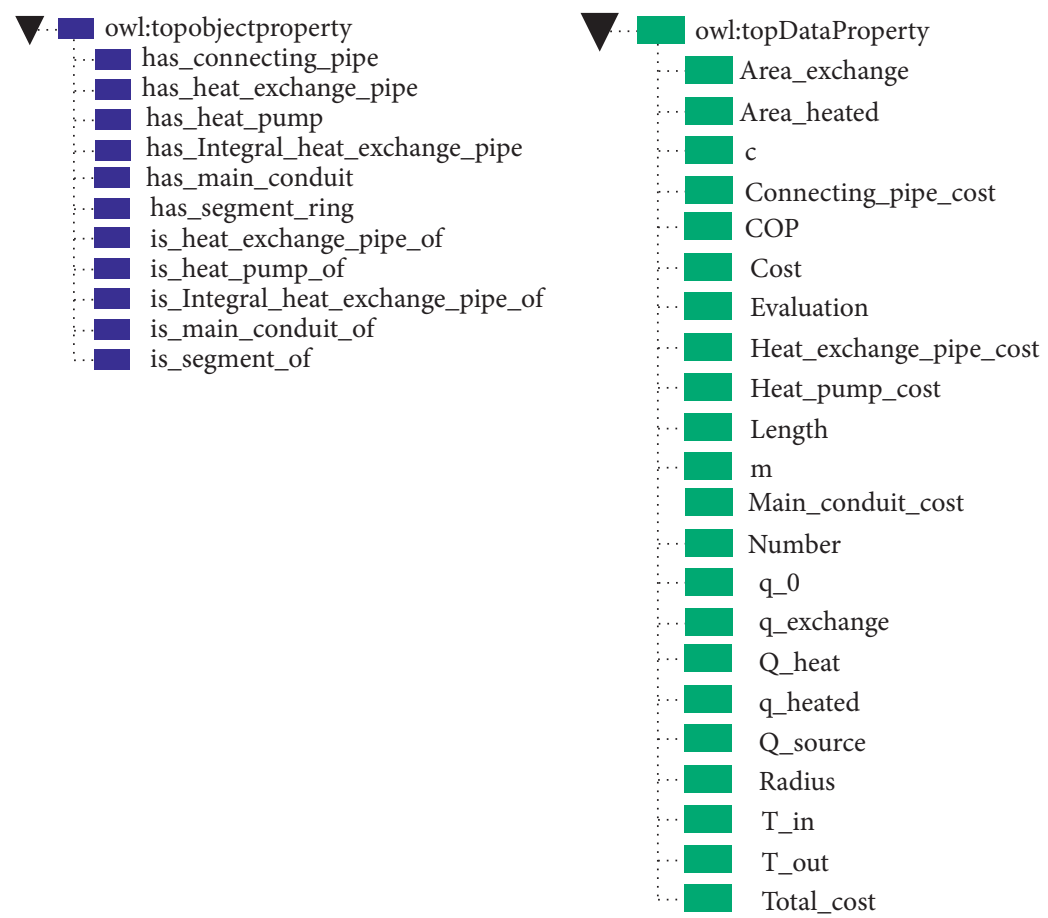

(b)

(c)

FIGURE 4: Class and property of developed ontology.

(2) Reusing the Existing Ontologies. The OWL language has the characteristics of interoperability. Therefore, the knowledge can be exchanged and shared between different ontologies. Thus, the existing ontology can be considered while constructing the ontology of the energy tunnel. The developed OntoETS decision-making system mainly uses IFC Standard as the term source. The existing ontology model of the ground source heat pump and energy tunnel are also considered.

(3) Enumerating the Important Terms of This Ontology. While establishing ontology, the terms and concepts form the framework of the entire domain knowledge. It should ensure the correctness of terms and the realization of the objective function of the ontology. The terms and concepts used in the ontology model developed in this study are shown in the UML flowchart of the OntoETS decisionmaking system (Figure 3 ).

(4) Defining Classes and Hierarchies of Classes. Defining the hierarchy of classes and classes is the most fundamental step in ontology development. The important terms enumerated in the previous step need to be developed from top to bottom according to different types. There are five classes in the energy-tunnel ontology established in this study: ground source heat pump system, geothermal exchange system, indoor system, tunnel structure, and materials. Each of these has subclasses. The specific details are shown in Figure 4(a).
(5) Defining the Properties of a Class. A class has two main types of properties: object properties and data properties. The objective relationship represents the relationship between classes. The relationships between classes constitute the framework of the domain knowledge. For example, the energy-tunnel system has a heat pump, i.e., the energytunnel system class and heat pump class can use the objective relationship has_ heat_ Pump to connect. Data properties represent the properties of the class, which are used to supplement data and enrich information. For example, the heat pump class has data properties such as unit price and quantity, i.e., the head pump has data properties such as cost and number. In general, Steps 4 and 5 can be carried out alternately while developing the ontology, which would reduce errors and omissions. These can also be completed following the above steps. Specific details of the characteristic are shown in Figures 4(b) and 4(c).

(6) Development of Instance. The instance established in this step is a real example of the class rather than an abstract concept. It has its own location and hierarchy as the class. Figure 5 shows the details of the establishment of an instance of the energy-tunnel system.

(7) Establishing SWRL Rules. Although ontology can be used to construct domain knowledge, many knowledge domains have logical relationship as well as data association. Therefore, the SWRL rules can be defined by the developer to strengthen the reasoning and computing capability of 


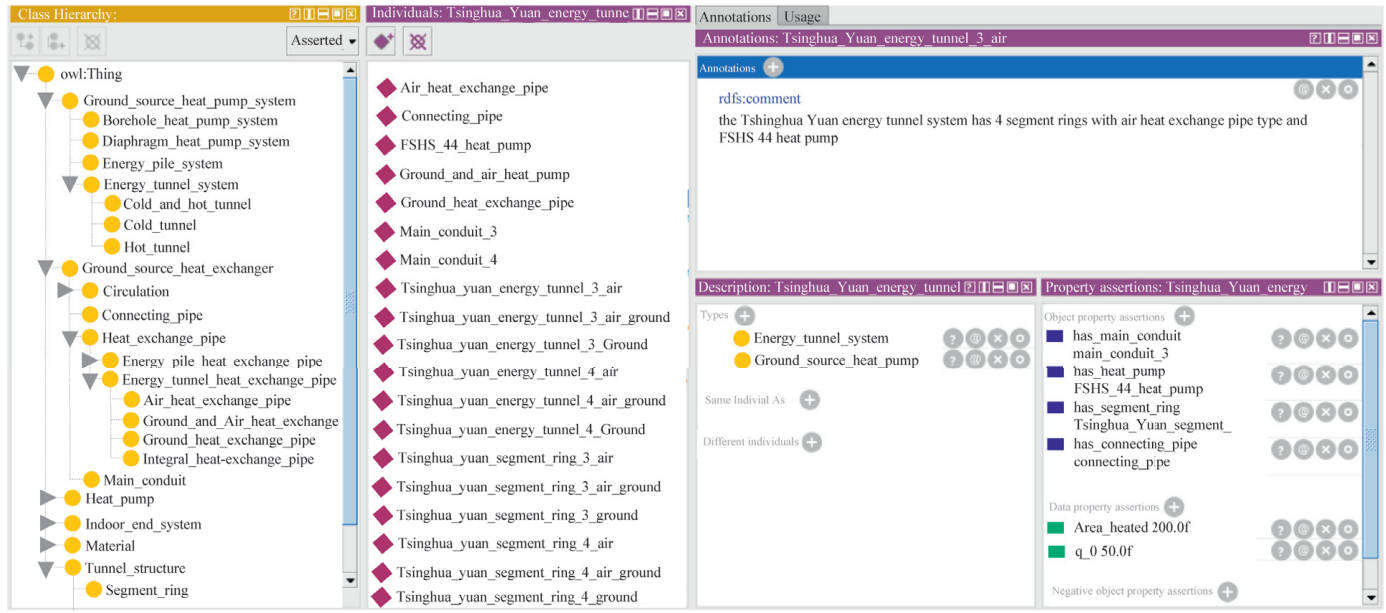

FIGURE 5: Development of an instance of the energy-tunnel system.

ontology. The SWRL rules of equipment cost of the energy tunnel is given as an example.

Energy_tunnel_system(?tunnel)Heat_exchange_pipe_cost(?tunnel,?absorb_cost)Main_conduit_cost(?tunnel,?cnd uit_cost)Connecting_pipe_cost(?tunnel,?connecting_cost)h eat_pump_cost(?tunnel,?pump_cost)'swrlb:add(?total_cost, ?absorb_cost, ?cnduit_cost, ?connecting_cost, ?pump_cost)$>$ Total_cost(?tunnel, ?total_cost).

(8) Establishing SWRL Rules. The OWL ontology is queried by establishing the corresponding rules through the web rules language (SQWRL rules) after ontology development. The designer can input the query requirements through the query interface, the plugin SQWRLTab can output the corresponding results, and the designer can design reasonably according to the query feedback results. The following uses a SQWRL rule to query all the information of the energy-tunnel system.

Energy_tunnel_system(?tunnel)Total_cost(?tunnel, ?total _cost)Connecting_pipe_cost(?tunnel, ?connecting_pipe_cost) Main_conduit_cost(?tunnel, ?main_conduit_cost)Heat_excha nge_pipe_cost(?tunnel,?heat_exchange_pipe_cost)Heat_pum p_cost(?tunnel, ?heat_pump_cost)Evaluation(?tunnel,?evaluation)Q_source(?tunnel, ?Qsource)Q_heat(?tunnel, ?Qheat) q_0(?tunnel, ?q0)q_heated(?tunnel, ?qheated)->sqwrl:select(? tunnel, ?heat_exchange_pipe_cost, ?main_conduit_cost,? total_cost, ?Qsource, ?Qheat, ?q0, ?qheated, ?evaluation).

2.3. Ontology Verification. The ontology needs to be validated to ensure the correctness of the model and the realization of the preset functions by the OntoETS decisionmaking system after ontology development. The validation includes semantic validation, syntax validation, and rule validation. The following is a description of the verification of the energy-tunnel ontology.

2.3.1. Semantic Validation. Semantic verification is performed to ensure the accuracy of the vocabulary and terms in the ontology model and to accurately describe and transfer domain knowledge. This study verified the semantics of the developed ontology by comparing, reusing, and merging the existing ontology. A newly established ontology would be effective if it reuses the existing ontology or vocabulary that has been verified [34-36]. The ontology model of the energy tunnel developed in this study mainly refers to the IFC Standard. As a general industry standard in the building, the correctness of the vocabulary has been verified. In addition, to better ensure the vocabulary accuracy of the energy-tunnel domain, it also refers to the existing ontology model of GSHP and energy-tunnel engineering. This is sufficient to demonstrate the semantic correctness of the ontology developed in this chapter.

2.3.2. Syntax Validation. Syntax validation is performed to ensure the correct hierarchical structure and logical relationship, which can accurately infer and calculate explicit and implicit relationships and data relationships in the ontology. In this study, the pellet reasoner in Protégé was selected to complete the syntax verification. It can examine the syntax of the ontology and remind logical exceptions in the ontology to help developers modify existing errors. The verification details are shown in Figure 6.

2.3.3. Rule Validation. Rule validation is performed to ensure that the developed rules are compatible with the established ontology and can enable accurate logical reasoning and data calculation. In this study, the SWRLTab plugin in Protégé is selected for the rule assessment. It can write and edit the rules and can report errors to the execution rules. If there is an error in the rules, the control command line of the plugin would display the failure and the overflow of the rules. The verification details are shown in Figure 7. For further system function verification, it would be carried out in the case study section.

It should be noted that the OntoETS presented in this study is a tool to enable multiobjective holistic decisionmaking for energy-tunnel system in the early stage of design. A case study in Section 3 will demonstrate the practicability and scientific feasibility of OntoETS. 


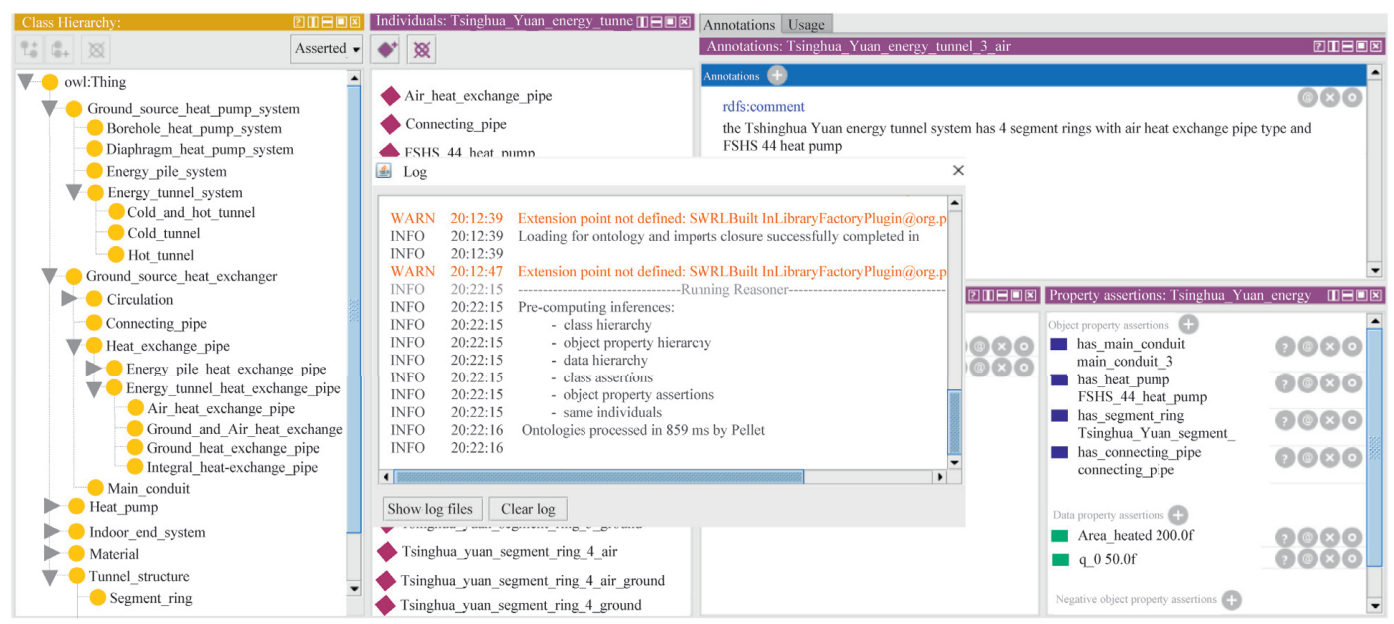

Figure 6: Log of execution pellet plugin to validate syntax of OntoETS.

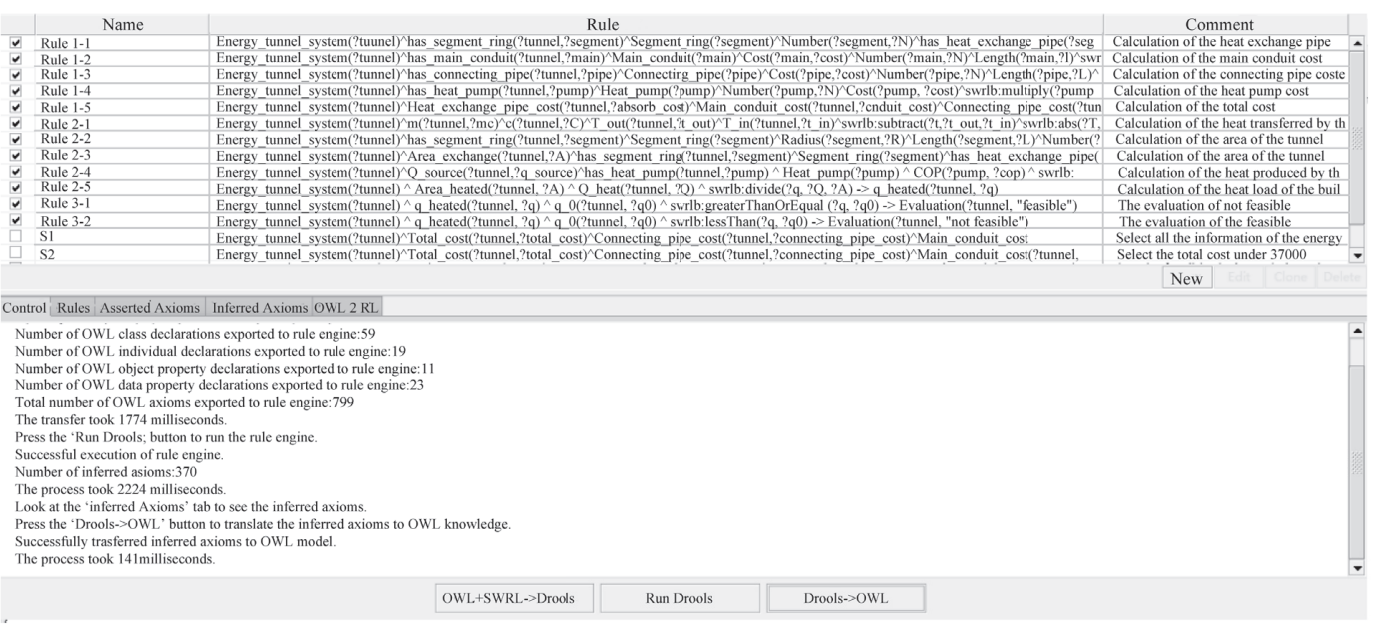

FIgURE 7: Execution log of rule assessment.

\section{Case Study}

Owing to the limited development time of energy-tunnel systems, there are few energy-tunnel application cases. Moreover, most of their data are missing. To ensure that the developed OntoETS decision-making system can closely approximate the actual project and verify the preset functions, the missing data of the case would be supplemented according to the regional experience and relevant specifications. Tsinghua University is selected in this section to obtain the maximum amount of reliable data. The energytunnel experiment of the Tsinghua Campus tunnel is used as the prototype for the case verification.

3.1. Case Study Description. The Tsinghua Campus tunnel was constructed by the shield method of Beijing Zhangjiakou Railway. The shield section has a length of approximately $4448.5 \mathrm{~m}$. The outer diameter of the tunnel is $12.2 \mathrm{~m}$. The segment thickness is $55 \mathrm{~cm}$, and the segment ring width is $2 \mathrm{~m}$. It was assembled by the " $6+2+1$ " mode.
The concrete design strength is C50, and the buried depth of the top of the tunnel is approximately $10 \mathrm{~m}$. The segment of the tunnel is used for the energy-tunnel experiment, wherein a hall with a building area of $200 \mathrm{~m}^{2}$ is heated.

According to the civil heating radiator published by Tsinghua University Press, the design heat flux of the building can be considered as $50 \mathrm{~W} / \mathrm{m}^{2}$. According to the building area, the system can be equipped with a FSHS-44 high-efficiency vortex ground source heat pump (unit price $=$ CNY 19000). The COP is conservatively considered as three, the price of the heat exchange pipe in the segment is $\mathrm{CNY} 6 / \mathrm{m}$, and the unit price of the main pipe and connecting pipe is CNY $30 / \mathrm{m}$. Three types of heat exchange tubes, and three-ring and four-ring tunnel segments are combined. A total of six design schemes are used to verify the developed OntoETS decision-making system. Details of the six design schemes are shown in Table 3. After setting the six design schemes, the ontology model would run according to the SWRL rules in Tables 4-6 with new facts and related data evaluation. 
Table 3: Details of six design schemes.

\begin{tabular}{|c|c|c|c|c|c|c|c|c|c|}
\hline \multirow{2}{*}{ Design scheme } & \multicolumn{2}{|c|}{ Segment ring } & \multicolumn{3}{|c|}{ The pipe of heat exchanger } & \multicolumn{2}{|c|}{ Connection pipe } & \multicolumn{2}{|c|}{ Main conduit } \\
\hline & Number & Radius (m) & Exchanger type & $q_{\text {exchange }}\left(\mathrm{w} / \mathrm{m}^{2}\right)$ & Length (m) & Number & Length (m) & Number & Length $(\mathrm{m})$ \\
\hline TY-ET-3-air & 3 & 6.1 & Air & 18 & 180 & 2 & 200 & 2 & 6 \\
\hline TY-ET-4-air & 4 & 6.1 & Air & 18 & 180 & 2 & 200 & 2 & 8 \\
\hline TY-ET-3-ground & 3 & 6.1 & Ground source & 30 & 180 & 2 & 200 & 2 & 6 \\
\hline TY-ET-4-ground & 4 & 6.1 & Ground source & 30 & 180 & 2 & 200 & 2 & 8 \\
\hline $\begin{array}{l}\text { TY-ET-3-air- } \\
\text { ground }\end{array}$ & 3 & 6.1 & Dual & 36 & 360 & 2 & 200 & 2 & 6 \\
\hline $\begin{array}{l}\text { TY-ET-4-air- } \\
\text { ground }\end{array}$ & 4 & 6.1 & Dual & 36 & 360 & 2 & 200 & 2 & 8 \\
\hline
\end{tabular}

TABLE 4: The SWRL rules of calculating cost.

Calculation the cost of the heat exchange pipe: $C^{\mathrm{TP}}=\sum_{i=1}^{n} C_{i}^{\mathrm{TP}} \times L_{i}^{\mathrm{TP}} \times N_{i}$ Energy_tunnel_system(?tunnel)has_segment
Rule 1 tunnel,?segment)Segment_ring(?segment)Number(?segment,?N)has_heat_exchange_pipe(?segment,?pipe) Energy_tunnel_heat_exchange_pipe(?pipe)Cost(?pipe,?cost)Length(?pipe,?L) ŝrwrlb:multiply(?pipe_cost,?L,?cost,?N)$>$ Heat_exchange_pipe_cost(?tunnel, ?pipe_cost)

Calculation the cost of the main conduit: $C^{\mathrm{MP}}=\sum_{j=1}^{n} C_{j}^{\mathrm{MP}} \times L_{j}^{\mathrm{MP}} \times N_{j}^{\mathrm{MP}}$ Energy_tunnel_system(?tunnel)has_main_conduit(?

Rule 2 tunnel,?main)Main_conduit (?main)'Cost(?main,?cost)Number(?main,?N)Length(?main,?l)swrlb:multiply (?conduit_cost,?l,? cost,?N) ->Main_conduit_cost(?tunnel, ?conduit_cost)

Calculation the cost of the connecting pipe: $C^{\mathrm{CP}}=\sum_{k=1}^{n} C_{k}^{\mathrm{CP}} \times L_{k}^{\mathrm{CP}} \times N_{k}^{\mathrm{CP}}$ Energy_tunnel_system(?tunnel)has_connecting_pipe(?

Rule 3 tunnel,?pipe)Connecting_ pipe(?pipe)Cost(?pipe,?cost)Number(?pipe,?N)Length(?pipe,?L)'swrlb:multiply(?pipe_cost, ?cost, ?L, ? N) ->Connecting_pipe_cost(?tunnel, ?pipe_cost)

Calculation the cost of the heat pump: $C^{\mathrm{HP}}=\sum_{l=1}^{n} C_{l}^{\mathrm{HP}} \times N_{l}^{\mathrm{HP}}$ Energy_tunnel_system(?tunnel)has_heat_pump(?tunnel,?pump)

Rule 4 Heat_pump (?pump)Number(?pump,?N)Cost(?pump, ?cost)'swrlb:multiply(?pump_cost, ?cost,?N)->Heat_pump_cost(?tunnel, ? pump_cost)

Calculation the total cost: $C^{\mathrm{E}}=C^{\mathrm{TP}}+C^{\mathrm{MP}}+C^{\mathrm{CP}}+C^{\mathrm{HP}}$ Energy_tunnel_system(?tunnel)Heat_exchange_pipe_cost(?tunnel,? absorb_cost) Main_conduit_cost(?tunnel,?conduit_cost)'Connecting_pipe_cost(?tunnel, ?connecting_cost)Heat_pump_cost(? tunnel,?pump_cost)'swrlb:add(?total_cost, ?absorb_cost,?conduit_cost,?connecting_cost,?pump_cost)->Total_cost(?tunnel, ? total_cost)

TABLE 5: SWRL rules for calculating exchanged heat and produced heat of the system.

Calculation of exchanged heat: $Q_{\text {source }}=m c\left|T_{\text {out }}-T_{\text {in }}\right|$ Energy_tunnel_system(?tunnel) $m($ ? tunnel,?mc) $c($ ?tunnel,?C) $T$ _out(?

Rule 1 tunnel,?t_out) T_in(?tunnel,?t_in)'swrlb:subtract(?t,?t_out,?t_in)swrlb:abs(?T,?t)swrlb: multiply(?Q, ?mc, ?M, ?T) ->Q_source(? tunnel, ?Q)

Calculation of heat exchanged area: $A_{i}^{\text {exchange }}=2 \times \pi \times R_{i} \times L_{i} \times N_{i}$ Energy_tunnel_system(?tunnel)has_segment_ring(?tunnel,?

Rule 2 segment)Segment_ring (?segment)Radius(?segment,?R)Length(?segment,?L)Number(?segment,?N) swrlb:multiply(?q_source,

3.14, 2, ?R, ?L, ?N) ->Area_exchange(?tunnel,?q_source)

Calculation of exchanged heat: $Q_{\text {source }}=\sum_{i=1}^{n} A_{i}^{\text {exchange }} \times q_{i}$ Energy_tunnel_system(?tunnel)Area_exchange(?tunnel,?A)

Rule 3 has_segment_ring (?tunnel,?segment)Segment_ring(?segment)has_heat_exchange_pipe(?segment, ?pipe)'q_exchange(?pipe, ? q_e)swrlb:multiply(?Q,?A,?q_e)->Q_source(?tunnel, ?Q)

Calculation of produced heat: $Q_{\text {heat }}=(\mathrm{COP} / \mathrm{COP}-1) \times \mathrm{Q}_{\text {source }}$ Energy_tunnel_system(?tunnel)Q_source(?tunnel,?q_source)

Rule 4 has_heat_pump (?tunnel,?pump)^Heat_pump(?pump)^COP(?pump, ?cop)^swrlb:subtract (?x, ?cop, 1)^swrlb:divide(?y, ?cop, ?x)^ swrlb:multiply(?q_heat, ?y, ?q_source) ->Q_heat(?tunnel, ?q_heat)

Rule 5 Calculation of heat flux: $q_{\text {heat }}=\left(Q_{\text {heat }} / A_{\text {heat }}\right)$ Energy_tunnel_system(?tunnel $)^{\wedge}$ Area_heated(?tunnel, ?A $)^{\wedge} \mathrm{Q} \_$heat $(? \text { tunnel, ?Q })^{\wedge}$ swrlb:divide(?q, ?Q, ?A) ->q_heated(?tunnel, ?q)

TABLE 6: The standard of system evaluation.

\begin{tabular}{|c|c|}
\hline ule 1 & $\begin{array}{c}\text { feasible: qheat } \geq \text { q0 Energy_tunnel_system(?tunnel)^q_heated(?tunnel, ?q)^ q_0(?tunnel, ?q0)^swrlb:greaterThanOrEqual (?q, ?q0) } \\
->\text { Evaluation(?tunnel, “feasible") }\end{array}$ \\
\hline ule 2 & $\begin{array}{r}\text { Not feasible: qheat< }<0 \text { Energy_tunnel_system(?tunnel)^q_heated(?tunnel, ?q)^q_0(?tunnel, ?q0)^swrlb:lessThan(?q, ?q0) } \\
->\text { Evaluation(?tunnel, "not feasible”) }\end{array}$ \\
\hline
\end{tabular}

After executing the OntoETS decision-making process, the input design scheme would carry out logical reasoning and data calculation according to the established ontology model and preset rules. Then, the reasoning interface with details as shown in Figure 8 can be obtained. On this basis, the designer can filter and optimize the design scheme by querying the interface according to different design requirements. 


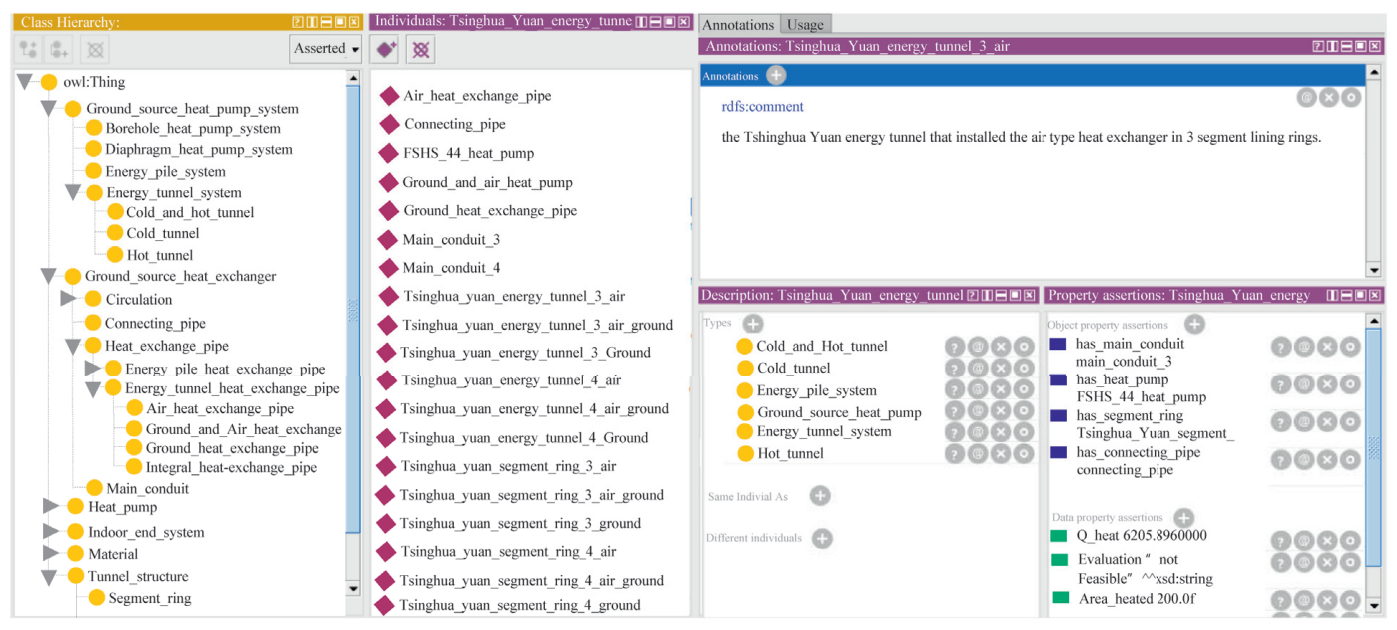

Figure 8: The inferencing interface of the OntoETS system.

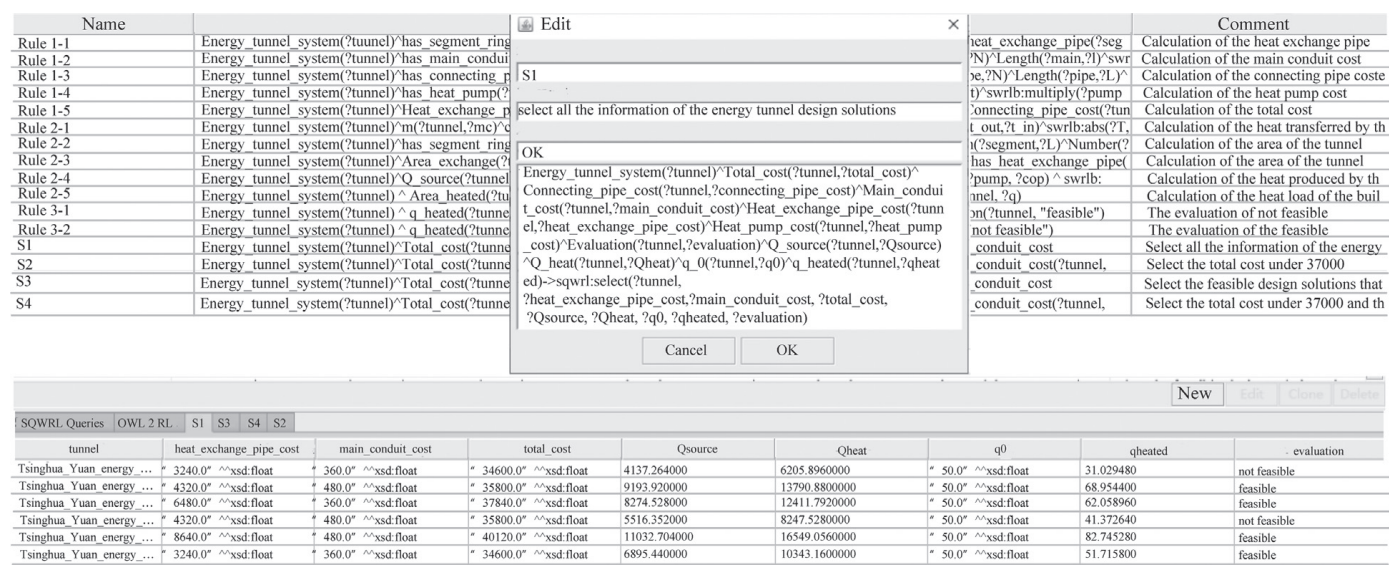

Figure 9: Execution and results of Table 7.

3.2. Applications. This section describes the validation of the preset functions of the OntoETS decision-making system and illustrates how the designer should use this tool to select and optimize the design scheme. After executing the decision-making system, the design scheme would generate new facts and relevant data evaluation according to the reasoner and preset SWRL rules. If the designer wishes to obtain the relevant information of all the design schemes (see Figure 9), the SQWRL rules shown in Table 7 can be used by querying the interface.

As shown in Figure 9, the relevant information of the six design schemes is displayed, such as cost, exchanged heat, heat generated by the system, building heat flux, and feasibility evaluation. If the design scheme requires further filtering and optimization, additional SQWRL rules can be used to optimize the design scheme. For example, if the design scheme needs to limit the total cost to within CNY 37000, the designer can input the SQWRL rule shown in Table 8 and obtain the return result of Figure 10.

As shown in Figure 10, there are four schemes with air source-type and ground source-type heat exchangers that satisfy the budget requirements. The design scheme with an air source-type heat exchange tube is not feasible because it cannot provide adequate heat flux for the building. Further selection is required if the design scheme and influencing factors are complex.

If the heat flux is the main design focus, the designer can input the SQWRL rule shown in Table 9 and obtain the return results as shown in Figure 11. The figure shows that four design schemes with ground source-type and dual-use heat exchange tubes satisfy the requirements. The designer can provide the general optimization direction on this basis. That is, the design scheme with a ground source-type heat exchanger or dual-use heat exchanger can satisfy the requirements. In addition, it can be optimized further in the design scheme wherein these two types of heat exchangera are installed.

All the above parameters are based on individual design requirements as query rules. Meanwhile, cost and heat flux are two important indicators to measure the energy-tunnel system that the designers would focus on. Furthermore, the optimal design scheme or detailed optimization direction can be produced by inputting SQWRL rules. The designer can input the SQWRL rule shown in Table 10 to select the design scheme with a cost below CNY 37000 and heat flux that satisfies the requirements. 
TABLE 7: SQWRL rule for selecting all the information of design schemes.

Energy_tunnel_system(?tunnel)Total_cost(?tunnel,?total_cost) Connecting_pipe_cost(?tunnel,?connecting_pipe_cost) Main_conduit_cost (?tunnel,?main_conduit_cost)Heat_exchange_pipe_cost(?tunnel,?heat_exchange_pipe_cost)

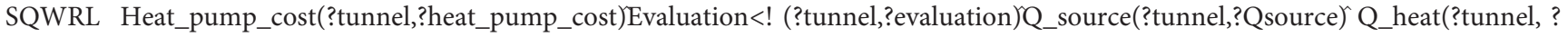
Qheat)'q_0(?tunnel,?q0)'q_heated(?tunnel,?qheated)->sqwrl: select(?tunnel, ?heat_exchange_pipe_cost,?main_conduit_cost, ? total_cost ?Qsource, ?Qheat, ?q0, ?qheated, ?evaluation)

TABLE 8: SQWRL rule for selecting design schemes with cost below CNY 37000.

Energy_tunnel_system(?tunnel)Total_cost(?tunnel,?total_cost)'Connecting_pipe_cost(?tunnel,?connecting_pipe_cost) Main_conduit_cost(?tunnel, ?main_conduit_cost)Heat_exchange_pipe_cost(?tunnel, ?heat_exchange_pipe_cost)

SQWRL Heat_pump_cost(?tunnel,?heat_pump_cost)Evaluation(?tunnel,?evaluation)Q_source(?tunnel,?Qsource)Q_heat(?tunnel, ? Qheat)'q_0(?tunnel, ?q0)'q_heated(?tunnel, ?qheated)'swrlb:lessThan(?total_cost,37000)->sqwrl:select(?tunnel, ? heat_exchange_pipe_cost, ?main_conduit_cost, ?total_cost, ?Qsource, ?Qheat, ?q0, ?qheated, ?evaluation)

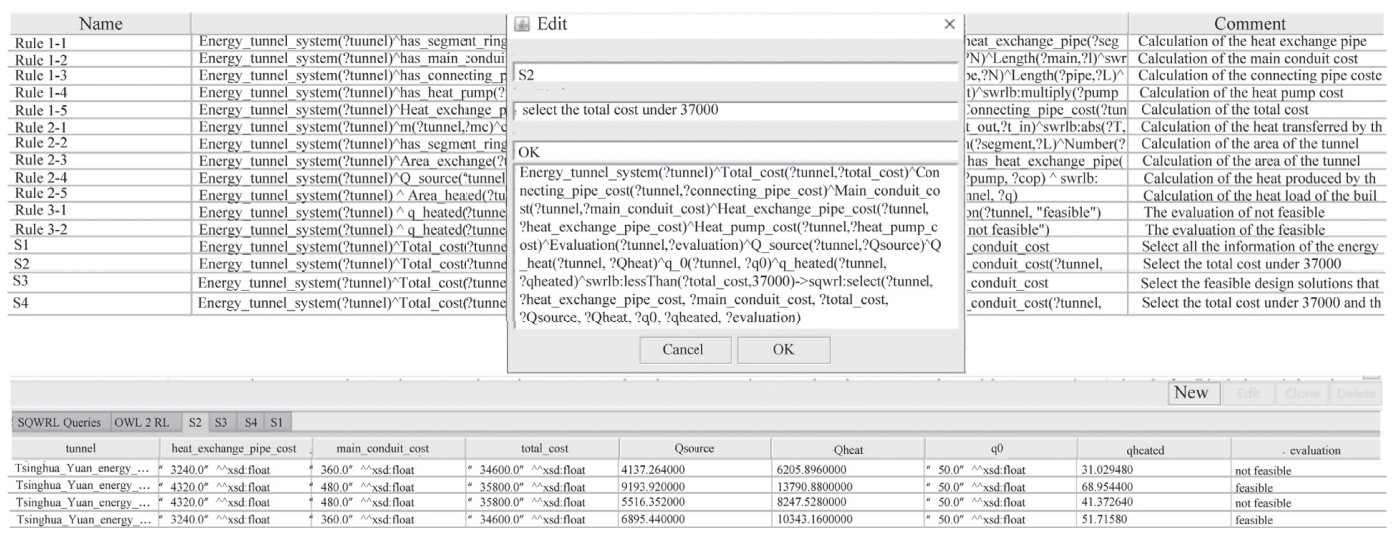

Figure 10: Execution and results of Table 8

TABLE 9: SQWRL rule for selecting design schemes with feasible heat flux.

Energy_tunnel_system(?tunnel)Total_cost(?tunnel,?total_cost)'Connecting_pipe_cost(?tunnel,?connecting_pipe_cost) Main_conduit_cost(?tunnel,?main_conduit_cost)Heat_exchange_pipe_cost(?tunnel,?heat_exchange_pipe_cost)

SQWRL Heat_pump_cost(?tunnel,?heat_pump_cost)Evaluation(?tunnel,?evaluation)Q_source(?tunnel,?Qsource)Q_heat(?tunnel,? Qheat)'q_0(?tunnel,?q0)q_heated(?tunnel,?qheated)swrlb:greaterThan(?qheated,?q0)->sqwrl:select(?tunnel,? heat_exchange_pipe_cost,?main_conduit_cost,?total_cost, ?Qsource,?Qheat,?q0, ?qheated, ?evaluation)

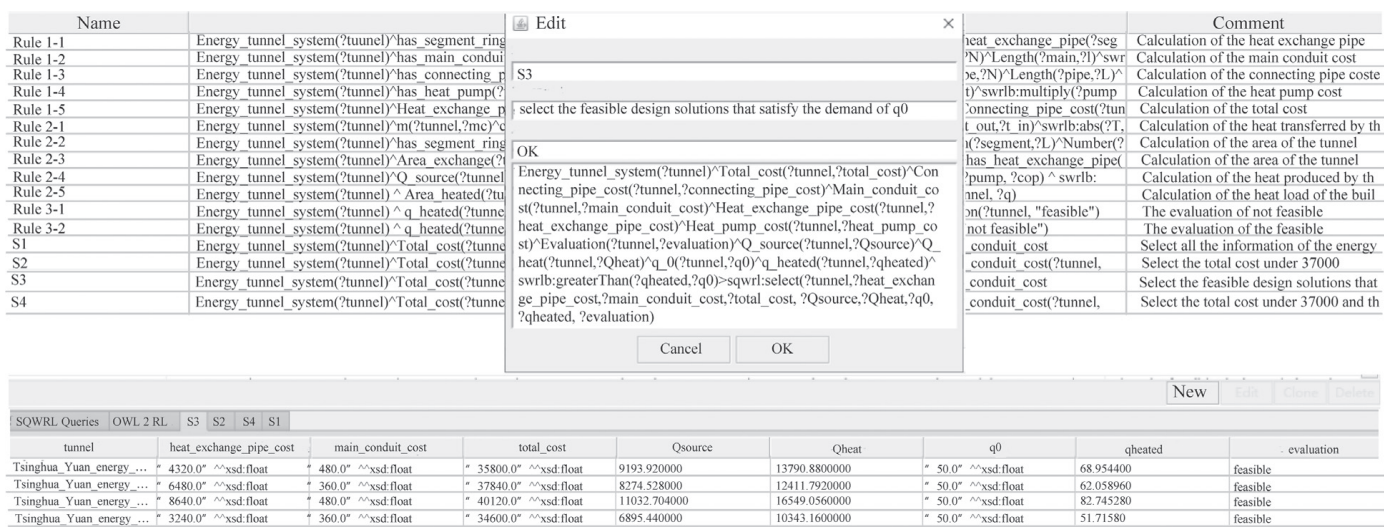

FIGURE 11: Execution and results of Table 9.

TABLE 10: SQWRL rule for selecting feasible design schemes with cost below $37000 \mathrm{CNY}$.

Energy_tunnel_system(?tunnel)Total_cost(?tunnel,?total_cost)'Connecting_pipe_cost(?tunnel,?connecting_pipe_cost) Main_conduit_cost(?tunnel,?main_conduit_cost)Heat_exchange_pipe_cost(?tunnel,?heat_exchange_pipe_cost)

SQWRL Heat_pump_cost(?tunnel,?heat_pump_cost)Evaluation(?tunnel,?evaluation)'Q_source(?tunnel,?Qsource)Q_heat(?tunnel,? Qheat)'q_0(?tunnel,?q0)'q_heated(?tunnel,?qheated)'swrlb:greaterThan(?qheated,?q0)'swrlb:lessThan(?total_cost,37000)->sqwrl: select(?tunnel, ?heat_exchange_pipe_cost, ?main_conduit_cost,?total_cost, ?Qsource, ?Qheat, ?q0, ?qheated, ?evaluation) 


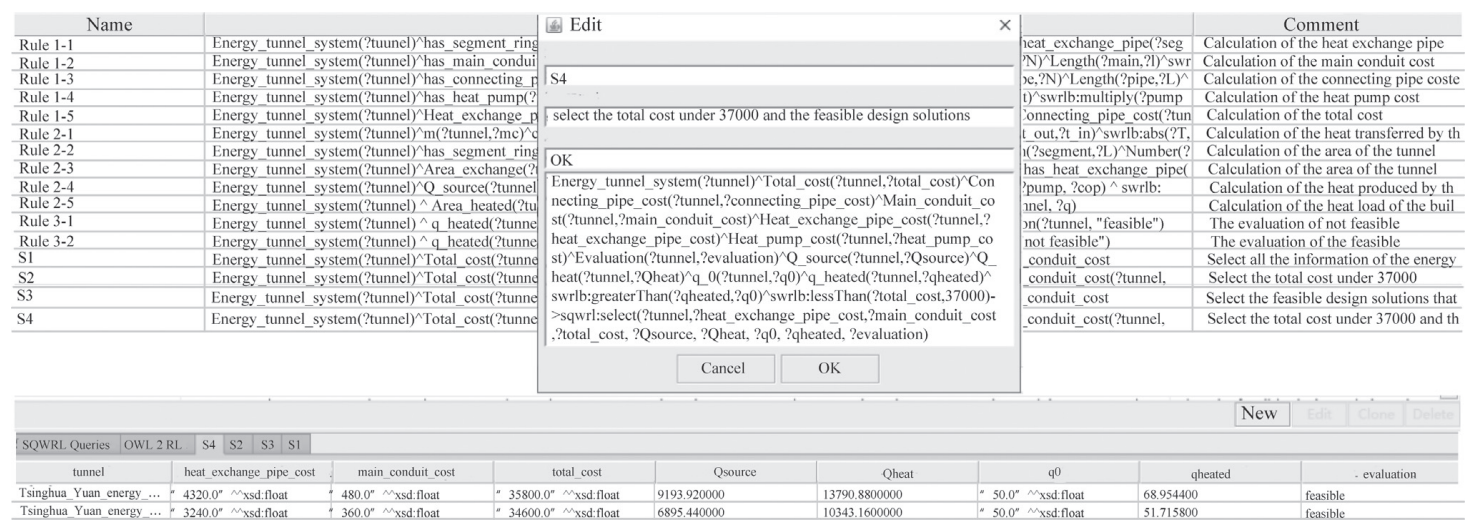

FIgURE 12: Execution and results of Table 10.

As shown in Figure 12, there are two designs that satisfy the requirements of both cost and heat flux. If required, designers can optimize further by varying the parameters of the energy tunnel (such as the number of segments, material of heat exchange tube, type of heat pump, and COP) and then reasoning and querying again to obtain the optimal scheme.

Through the above steps, the designer can generally obtain the design scheme that satisfies the design requirements and generate the optimization direction. This case study is performed only to verify whether the OntoETS decision-making system can achieve its predetermined functions and does not design a complex energy-tunnel system. The influencing factors when an actual energytunnel design scheme is carried out are more complex, and the OntoETS decision-making system will show more prominent advantages of holistic design.

\section{Conclusions}

The OntoETS decision-making system developed in this study can design complex technical energy tunnels holistically and evaluate from a macroperspective to promote the optimal design scheme. Thereby, the designers can obtain multiple performance indicators from a macroperspective (such as cost, heat flux, and system feasibility) by using this tool to select and optimize the design scheme. This can improve design efficiency and promote the application of energy tunnels.

This study combined the ontology and SWRL rule to construct the domain knowledge of energy tunnels, which is an enrichment of the conventional GSHP domain knowledge. It can prevent loss caused by information distortion in different disciplines and stages. Furthermore, to ensure the correctness of the developed ontology, the IFC standard is considered as the fundamental classification standard and the vocabulary of existing ontology is also considered as reference. In addition, the correctness of the syntax and rules is also conducted. Finally, to verify the preset function of the system, a case study was conducted to assess the correctness of its logical relationship and data association. The case study demonstrates how designers should use the OntoETS decision-making system for a holistic design so as to achieve the best combination of cost, heat, heat flux, and other indicators of energy-tunnel systems and produce the optimal design scheme.

The OntoETS decision-making system (which is designed for holistic design of energy-tunnel systems) essentially uses the ontology's advantages of crossing the domain to carry out implicit or apparent logical relationship reasoning and data association. This is to promote the exchange and sharing of data, which is consistent with the concept of BIM. Relevant scholars have also conducted substantial research on the application of ontology in BIM. In future study, the ontology technology and SWRL rules can be applied to develop ontology decision-making systems with unified interfaces in different fields. This would enable collaborative design by different disciplines, industries, and stages in the entire life cycle.

\section{Data Availability}

The data used to support the findings of this study are available from the corresponding author upon request.

\section{Conflicts of Interest}

The authors declare no conflicts of interest.

\section{Acknowledgments}

This work was supported by the National Natural Science Foundation of China (Grant nos. 52178315 and 51878109), the National Science Foundation for Young Scientists of China (Grant no. 52108326), the National Science Fund for Excellent Young Scholars of China (Grant no. 51722801), the Fundamental Research Funds for the Central Universities (Grant no. 3132019601), and Cultivation Project of Innovation Talent for Doctorate Student (CXXM2019BS008 and BSCXXM022).

\section{References}

[1] L. Laloui and A. Di Donna, "Understanding the behaviour of energy geo-structures[J]," Proceedings of the Institution of Civil Engineers Civil Engineering, vol. 164, no. 4, pp. 184-191, 2011.

[2] B. X. Yuan, Z. H. Li, and Z. Q. Zhao, "Experimental study of displacement field of layered soils surrounding laterally loaded pile based on Transparent Soil [J]," Journal of Soils and Sediments, vol. 21, pp. 3072-3083, 2021. 
[3] K. Meng, C. Y. Cui, Z. M. Liang, H. Li, and H. Pe, "A new approach for longitudinal vibration of a large-diameter floating pipe pile in visco-elastic soil considering the threedimensional wave effects," Computers and Geotechnics, vol. 128, Article ID 103840, 2020.

[4] B. Bai, R. Zhou, and G. Q. Cai, "Coupled thermo-hydromechanical mechanism in view of the soil particle rearrangement of granular thermodynamics," Computers and Geotechnics, vol. 137, no. 8, Article ID 104272, 2021.

[5] C. Y. Cui, K. Meng, and C. X. Xu, "Analytical solution for longitudinal vibration of a floating pile in saturated porous media based on a fictitious saturated soil pile model," Computers and Geotechnics, vol. 131, Article ID 103942., 2021.

[6] H. Brandl, "Energy foundations and other thermo-active ground structures[J]," Géotechnique, vol. 56, no. 2, pp. 81-122, 2006.

[7] M. Barla and A. Di Donna, "Energy tunnels: concept and design aspects[J]," Underground Space, vol. 3, no. 4, pp. 268-276, 2018.

[8] M. Barla, A. Di Donna, and A. Perino, "Application of energy tunnels to an urban environment," Geothermics, vol. 61, pp. 104-113, 2016.

[9] D. P. Nicholson, Q. Chen, M. de Silva, W. Alan, and W. Ralf, "The design of thermal tunnel energy segments for Crossrail, UK," Proceedings of the Institution of Civil Engineers-Engineering Sustainability, Thomas Telford Ltd, vol. 167, no. 3, pp. 118-134, 2014.

[10] S. Frodl, J. N. Franzius, and T. Bartl, "Design and construction of the tunnel geothermal system in Jenbach," Geomechanics and Tunnelling, vol. 3, no. 5, pp. 658-668, 2010.

[11] M. S. Islam, T. Fukuhara, H. Watanabe, and N. Akiko, "Horizontal U-tube road heating system using tunnel ground heat," Journal of Snow Engineering of Japan, vol. 22, no. 3, pp. 229-234, 2006.

[12] D. Adam and R. Markiewicz, "Energy from earth-coupled structures, foundations, tunnels and sewers," Géotechnique, vol. 59, no. 3, pp. 229-236, 2009.

[13] G. Zhang, C. Xia, M. Sun, Z. Yichuan, and X. Suguang, "A new model and analytical solution for the heat conduction of tunnel lining ground heat exchangers," Cold Regions Science and Technology, vol. 88, pp. 59-66, 2013.

[14] M. S. Islam, T. Fukuhara, and H. Watanabe, "Simplified heat transfer model of horizontal U-tube (HUT) system," Journal of Snow Engineering of Japan, vol. 23, no. 3, pp. 232-239, 2007.

[15] M. Barla and A. Perino, "Energy from geo-structures: a topic of growing interest[J]," Environmental geotechnics, vol. 2, no. 1, pp. 3-7, 2015.

[16] C. Yang, F. L. Peng, K. Xu, and Z. Li-Ning, "Feasibility study on the geothermal utility tunnel system," Sustainable Cities and Society, vol. 46, Article ID 101445, 2019.

[17] A. Bidarmaghz and G. A. Narsilio, "Heat exchange mechanisms in energy tunnel systems," Geomechanics for Energy and the Environment, vol. 16, pp. 83-95, 2018.

[18] E. Sailer, D. M. G. Taborda, and J. Keirstead, Fortieth Workshop on Geothermal Reservoir Engineering: Assessment of Design Procedures for Vertical Borehole Heat Exchangers, Stanford University, Stanford, CA, USA, 2015.

[19] J. Fadejev, R. Simson, J. Kurnitski, and H. Fariborz, "A review on energy piles design, sizing and modelling," Energy, vol. 122, pp. 390-407, 2017.

[20] K. Zhang and P. C. Liao, "Ontology of ground source heat pump," Renewable and Sustainable Energy Reviews, vol. 49, pp. 51-59, 2015.
[21] P. Kogut, S. Cranefield, L. Hart et al., "UML for ontology development," The Knowledge Engineering Review, vol. 17, no. 1, pp. 61-64, 2002.

[22] B. Chandrasekaran, "AI, knowledge, and the quest for smart systems,” IEEE Expert, vol. 9, no. 6, pp. 2-5, 1994.

[23] O. O. Ugwu, C. J. Anumba, and A. Thorpe, "Ontology development for agent-based collaborative design," Engineering Construction and Architectural Management, vol. 8, no. 3, pp. 211-224, 2001.

[24] S. Hou, H. Li, and Y. Rezgui, "Ontology-based approach for structural design considering low embodied energy and carbon," Energy and Buildings, vol. 102, pp. 75-90, 2015.

[25] L. Zhang and R. R. A. Issa, "IFC-based construction industry ontology and semantic web services framework," in Proceedings of the Computing in Civil Engineering (2011), Miami, FL, USA, June 2011.

[26] C. J. Anumba, J. Pan, R. R. A. Issa, and I. Mutis, “Collaborative project information management in a semantic web environment," Engineering Construction and Architectural Management, vol. 15, no. 1, pp. 78-94, 2008.

[27] R. Peachavanish, H. A. Karimi, B. Akinci, and B. Frank, "An ontological engineering approach for integrating CAD and GIS in support of infrastructure management," Advanced Engineering Informatics, vol. 20, no. 1, pp. 71-88, 2006.

[28] M. P. Nepal, S. Staub-French, R. Pottinger, and Z. Jiemin, "Ontology-based feature modeling for construction information extraction from a building information model," Journal of Computing in Civil Engineering, vol. 27, no. 5, pp. 555-569, 2013.

[29] E. Sirin, B. Parsia, B. C. Grau, K. Aditya, and K. Yarden, "Pellet: a practical OWL-DL reasoner," Journal of Web Semantics, vol. 5, no. 2, pp. 51-53, 2007.

[30] C. Han and X. B. Yu, "Feasibility of geothermal heat exchanger pile-based bridge deck snow melting system: a simulation based analysis," Renewable Energy, vol. 101, pp. 214-224, 2017.

[31] L. Zhang and R. R. A. Issa, "Ontology-based partial building information model extraction," Journal of Computing in Civil Engineering, vol. 27, no. 6, pp. 576-584, 2013.

[32] T. Beach, Y. Rezgui, H. Li, and T. Kasim, "A rule-based semantic approach for automated regulatory compliance in the construction sector," Expert Systems with Applications, vol. 42, no. 12, pp. 5219-5231, 2015.

[33] H. Liu, P. Maghoul, A. Bahari, and K. Miroslava, "Feasibility study of snow melting system for bridge decks using geothermal energy piles integrated with heat pump in Canada," Renewable Energy, vol. 136, pp. 1266-1280, 2019.

[34] M. NoynF, "Interactive tools for ontology merging and mapping[J]," International Journal of Human-Computer Studies, vol. 59, no. 6, pp. 983-1024, 2003.

[35] E. Hovy, The Semantics of Relationships: Comparing Sets of Semantic Relations in Ontologies, Springer, Dordrecht, Netherlands, 2002.

[36] N. F. Noy and D. L. McGuinness, Ontology Development 101: A Guide to Creating Your First Ontology, Stanford University, Stanford, CA, USA, 2001. 